Authors' copy of paper to be published in Personality \& Individual Differences.

This is not the copy of record.

\title{
A REINFORCEMENT SENSITIVITY THEORY EXPLANATION OF ANTISOCIAL BEHAVIOUR
}

\author{
Alison M. Bacon ${ }^{1}$ \\ Philip J. Corr ${ }^{2}$ \\ Liam Paul Satchell ${ }^{3}$ \\ ${ }^{1}$ School of Psychology, University of Plymouth, UK \\ ${ }^{2}$ Department of Psychology, City, University of London, UK \\ ${ }^{3}$ Department of Law and Criminology, University of West London, UK
}

Corresponding author:

Dr Alison M. Bacon

School of Psychology

Plymouth University

Drake Circus

Plymouth PL4 8AA

Tel: 01752584805

Fax: 01752584808

Email: ambacon@plymouth.ac.uk 
RUNNING HEAD: RST AND ANTISOCIAL BEHAVIOUR

\begin{abstract}
A comprehensive explanation of antisocial behaviour (ASB) needs to focus on both individual differences in personality and life events as potentially predisposing factors. The current studies investigated the relative influence of both of these in males and females. We used the Reinforcement Sensitivity Theory (RST) of personality to investigate the extent to which dispositional approach and avoidance tendencies relate to ASB. In the first study, 287 participants reported their engagement in ASB and completed the RST Personality Questionnaire (RST-PQ). In the second study, a new sample of 282 participants completed the same measures as well as reporting the extent to which they had experienced life strains. Results from both studies showed a positive association between goal-drive persistence and ASB in males; while in females, a positive association was found between impulsivity and ASB. In Study 2, life strains explained further variance in ASB and this also show a gender differentiation: in males, there was a stronger relationship between financial strains and ASB while females showed an association between relational strains and ASB. Overall, results suggested that ASB is more pronounced in the male sample with an instrumental purpose while in the female sample personal life events are of more relevance.
\end{abstract}

Keywords: reinforcement sensitivity theory; antisocial behaviour; strain; sex-differences 
To understand, prevent and deter antisocial behaviour (ASB), we need to develop a more comprehensive understanding of the systematic individual differences in personality involved in the proclivity to engage in antisocial behaviour. The two studies reported in this paper seek to address this issue in terms of the strength of dispositional approach and avoidance motivation. We define ASB in terms of the description offered by Rutter (2003), who suggested that it can be characterized as nonconformity, and disregard or unwillingness to adhere to rules and obligations imposed by society or social organizations. As such, ASB may include criminal acts that violate specific laws, but also behaviours which are not in themselves illegal but which contradict the social values and norms (e.g., cheating in examinations). Accordingly, ASB is not the sole preserve of forensic samples and can be measured within the general population - this view is supported by evidence which shows that $74 \%$ of people self-report committing at least one 'microcrime' (a very minor offence) in their life (YouGov, 2016).

Antisocial behaviour peaks in adolescence and for many individuals this is a relatively benign and short-lived stage in the transition to adulthood (Moffitt, 1993, 2006) - indeed, many adolescents engage in activities that could be considered antisocial. Given that it is somewhat "normal" to engage in limited antisocial behaviour (particularly in adolescence), but rare to continue to engage during adulthood, normative models of understanding systematic individual differences, especially personality, may help better to understand the psychology of antisocial acts. One such theory, that encompasses key risk factor traits of impulsivity, self-control and goal-drive persistence, is the Reinforcement Sensitivity Theory (RST) of Personality (Corr, 2008).

Reinforcement Sensitivity Theory (RST) is a prominent neuropsychological theory of personality, conceptualised in terms of emotion, motivation, and learning (Corr \& McNaughton, 2012). RST is founded on the assumption that underpinning all major 
RUNNING HEAD: RST AND ANTISOCIAL BEHAVIOUR

personality traits are basic systems of approach and avoidance (Corr, 2015; Corr, DeYoung, \& McNaughton, 2013). As detailed by Corr and Krupić (2017), individuals construct their own approach and avoidance related goals and this shapes the nature of the reinforcement to which they are sensitive and, thus, to which they react.

RST describes a behavioural approach system (BAS), defined as being sensitive to appetitive stimuli and producing motivated goal-directed approach behaviours (Gray \& McNaughton, 2000). The main function of the BAS is to move the organism along a spatiotemporal gradient towards a final biological reinforcer. In order to reach this goal, there are a number of distinct but related BAS processes: "reward interest" and "goal-drive persistence" characterize the early stages of approach and these factors can be distinguished from "reward reactivity" and "impulsivity" which are concerned with processes closer to the final reinforcer (Corr \& Cooper, 2016). Activation of the BAS is said to lead to the experience of hopeful excitement, drive persistence to reach desired goals, and elation when they have been attained (Corr, DeYoung, \& McNaughton, 2013).

A second system, the Fight-Flight-Freeze System (FFFS), mediates reactions to all aversive stimuli (conditioned or otherwise), leading to avoidance and escape behaviours. A third system, the behavioural inhibition system (BIS), is specifically sensitive to goal-conflict (e.g., equal activation of the FFFS and BAS - or, indeed, goal conflict of any kind with sufficient motivational intensity) and it motivates passive avoidance behaviour. As such, the BIS is responsible for detecting and resolving conflict, rather than simply being sensitive to punishing stimuli, and contributes to risk assessment and potentially to rumination, which can result in the experience of anxiety. This RST structure is now widely recognized, in conceptual and psychometrical terms (Corr, 2011; Gray \& McNaughton, 2000; Perkins, Kemp, \& Corr, 2007; for review, see Corr, 2016; Corr \& Cooper, 2016). 
RUNNING HEAD: RST AND ANTISOCIAL BEHAVIOUR

The RST of personality is of interest to ASB given the extant evidence. For example, impulsivity has consistently been implicated in adolescent ASB (Maneiro, Gómez-Fraguela, Cutrín, \& Romero, 2016) as has the related construct of sensation seeking - that is, the tendency to desire and actively seek out novel and intensely stimulating experiences and the willingness to take risks for the sake of these 'thrills' (Zuckerman, 1994). A large body of research has suggested that high levels of sensation seeking may be a risk factor for criminal and antisocial behaviours in student, community and convicted samples (Gomà-i-Freixanet, 1995; Hansen \& Breivik, 2001; Horvath \& Zuckerman, 1993; Pfefferbaum \& Wood, 1994; Zuckerman, 2007). In line with the age-related prevalence of ASB, sensation seeking tends to peak in adolescence (Zuckerman, 2007). Other personality traits that have been associated with ASB include lower than average levels of social competence (Palmer \& Hollin, 1999), lack of empathy (Jolliffe \& Farrington, 2007; Cohen \& Strayer, 1996) and impaired emotional and physical self-regulation (Eisenberg et al., 1996; Gottfredson \& Hirschi, 1990; Moffitt et al., 2011). Accordingly, antisocial individuals have been shown to score less highly on measures of related constructs such as cognitive ability (Brackett, Mayer, \& Warner, 2004) and trait-emotional intelligence (Bacon et al., 2014), though the latter finding was found only for a male sample (no such finding was present in the female sample).

Little research to date has explored the contribution of RST personality factors to ASB. In one study, Morgan et al. (2014) indicated heightened BAS and lowered BIS in a sample of male antisocial adolescents, as compared with a non-offending sample. These findings present a useful insight into motivational drive towards ASB. However, Morgan et al. used an RST questionnaire measure (Carver \& White, 1994) which assesses personality factors on the basis of the original conceptualisation of the theory (Gray, 1982) - specifically, they measured BIS and BAS as unitary concepts and did not include a measure of the FFFS. 
As such, their results did not take into account the most recent developments in RST (Corr, 2016; Corr \& Cooper, 2016).

In the present two studies, we employed a contemporary and more comprehensive psychometric approach that differentiates FFFS and BIS, as well as providing a more nuanced conceptualisation and measurement of the BAS (Corr \& Cooper, 2016). In addition, Morgan et al.'s (2014) study comprised only male participants - males typically report higher levels of ASB than females especially for more criminal and violent activities, although the gender gap narrows when minor offences are taken into account. It is also known that, as a group, males score more highly on measures of sensation seeking (Zuckerman, 1994, 2007). In the present research, we explored possible gender differences in the relationships between ASB and an expanded theoretical and psychometric definition of RST personality factors.

\section{Study 1}

In Study 1, our aim was to examine the relationship between ASB in adolescence and emerging adulthood and personality traits assessed within the revised RST framework. In line with what is known about personality and ASB, we predicted a positive association between levels of ASB and impulsivity for both males and females. Given Morgan et al's (2014) study, we also expected to observe a positive association between ASB and BAS traits and a negative association with BIS.

\section{Method}

Participants

Two hundred and eighty-seven undergraduates participated in return for course credit: 169 females $\left(M^{\text {age }}=20.66, S D=2.44\right)$ and 118 males $\left(M^{\text {age }}=20.29, S D=2.12, p=.21, d=\right.$ $.16)$. 


\section{RUNNING HEAD: RST AND ANTISOCIAL BEHAVIOUR}

\section{Materials and procedures}

Antisocial behaviour: We presented a list of 35 behaviours and participants were asked to respond yes to any they had engaged in since the age of 12 years. Items ranged across non-illegal but undesirable behaviours, such as cheating in an exam, interpersonal behaviours such as bullying, relatively minor criminal offences such as using public transport without a ticket to more serious offences such as assault. This method has been used in previous published research on ASB (Bacon et al, 2014; Bacon, Lenton-Maughan \& May, in press). Scores were obtained by summing the yes responses to provide an overall ASB score which presented good reliability $(\alpha=.88)$.

\section{Reinforcement Sensitivity Theory of Personality Questionnaire (RST-PQ, Corr \&} Cooper, 2016). This 65-item scale measures three major systems: Fight/Flight/Fear System (FFFS; e.g., "I am the sort of person who easily freezes-up when scared"); Behavioural Inhibition System (BIS; e.g., "When trying to make a decision, I find myself constantly chewing it over"); and four Behavioural Approach System (BAS) factors: Reward Interest (e.g., "I regularly try new activities just to see if I enjoy them"), Goal-Drive Persistence (e.g., "I am very persistent in achieving my goals"), Reward Reactivity (e.g., "I get a special thrill when I am praised for something I've done well"), and impulsivity (e.g., "I find myself doing things on the spur of the moment"). Participants respond on a scale from 1 (not at all) to 5 (highly). The RST-PQ scales presented good internal reliability with the present sample: $\mathrm{FFFS}=.79 ; \mathrm{BIS}=.94 ; \mathrm{BAS}$ reward interest $=.79 ; \mathrm{BAS}$ goal-drive persistence $=.87 ; \mathrm{BAS}$ reward reactivity $=.81 ;$ BAS impulsivity $=.70$.

Social Economic Status (SES): We collected family background SES as a control measure. Participants were shown a list of six occupational levels based on the NRS social grades, a system of demographic classification used in the UK for market research purposes (Market Research Society, 2016). The SES levels were coded from 1 (long-term unemployed, 
for whatever reason) to 6 (professional occupations). Participants were asked to indicate which best reflected the home where they grew up and as such, higher score suggested a higher family SES.

Ethical approval was obtained from the university faculty ethics committee. All participants completed the following measures presented online via the Survey Monkey platform.

\section{Analysis}

Analysis was conducted using SPSS version 22. Gender differences in ASB were calculated by an independent samples t-test and in the RST factors by a multivariate analysis of variance (MANOVA). Associations between variables were examined using Pearson's product moment correlations (two-tailed). Linear multiple regression was used to examine the extent to which the RST factors could account for variance in ASB. For each RST factor score, values for skewness and kurtosis fell well within the acceptable range of between -2 and +2 suggesting the data were close to normally distributed (West et al, 1995). ASB scores showed negatively skewed distributions as participants tended to report fairly low levels (as we might expect with a non-forensic population). However, on calculating the regressions residuals, scores were found to be normally distributed suggesting the assumptions unpinning regression were not violated.

\section{Results}

Table 1 presents descriptive statistics for the male and female samples. The reported SES for the male $(M=3.82, S D=1.86)$ and female $(M=3.94, S D=1.76)$ samples did not significantly differ $(p=.42, d=.07)$. 
RUNNING HEAD: RST AND ANTISOCIAL BEHAVIOUR

Table 1. Descriptive statistics for males and females in Study 1

\begin{tabular}{lcccc}
\hline & \multicolumn{2}{c}{ Males } & \multicolumn{2}{c}{ Females } \\
& Mean & SD & Mean & SD \\
\cline { 2 - 5 } ASB & 15.41 & 9.10 & 12.39 & 8.14 \\
BAS Reward interest & 16.52 & 4.10 & 17.27 & 4.11 \\
BAS Goal drive persistence & 18.78 & 4.59 & 21.06 & 4.45 \\
BAS Reward reactivity & 25.44 & 5.26 & 28.43 & 5.25 \\
BAS Impulsiveness & 19.68 & 4.70 & 18.50 & 4.71 \\
BIS & 60.43 & 13.81 & 61.20 & 14.36 \\
FFFS & 21.42 & 5.70 & 24.12 & 5.82 \\
\hline
\end{tabular}

BAS $=$ Behavioural Approach System, FFFS $=$ Fight $/$ Flight $/$ Freeze System, BIS $=$ Behavioural Inhibition System

We found a higher level of ASB in the male sample: $t(285)=2.94, p=.003, d=.35$. A Multivariate analysis of variance (MANOVA) on the RST factors indicated significant effects of gender on goal-drive persistence $F(1,285)=17.72, p<.001, \eta^{2}=0.6$, reward reactivity $F(285)=22.49, p<.001, \eta^{2}=.07$, and FFFS $F(285)=15.19, p<.001, \eta^{2}=.05$, with higher scores in the female sample. Males however score more highly than females on impulsivity $F(285)=4.36, p=.03, \eta 2=.02$ and Table 2 presents partial correlations between these measures, controlling for SES. The largest correlation between RST-PQ factors and Antisocial Behaviour (ASB) was found for BAS-impulsivity. This fits with previous research suggesting that spontaneity and poor planning contributes to antisocial conduct. For the male sample, there were positive correlations between ASB and reward interest, goal-drive persistence and the BIS; in contrast, in the female sample, we found a negative association between ASB and goal-drive persistence only. 
Table 2. Study 1, Pearson's r correlations, controlling for SES, between Antisocial Behaviour and RST traits for whole sample, and female and male samples, with Fisher's Z test for sex-difference between correlations.

\begin{tabular}{lcccc}
\hline & Whole Sample & Female & Male & Fisher's $Z$ \\
\hline \multicolumn{1}{c}{$\underline{\text { Study } 1}$} & & & & \\
BAS-RI & 0.04 & 0.06 & 0.05 & 0.08 \\
BAS-GDP & -0.03 & $-0.25^{*}$ & $0.34^{* *}$ & $5.02^{* *}$ \\
BAS-RR & 0.16 & 0.08 & $0.39^{* *}$ & $2.73^{*}$ \\
BAS-Imp & $0.40^{* *}$ & $0.47^{* *}$ & $0.38^{* *}$ & 0.91 \\
FFFS & -0.08 & -0.11 & 0.05 & 1.32 \\
BIS & 0.16 & 0.12 & 0.23 & 0.94 \\
\hline
\end{tabular}

BAS= Behavioural Approach System, RI= Reward Interest, GDP= Goal-Drive Persistence, RR= Reward Reactivity, Imp= Impulsivity, FFFS= Fight/Flight/Freeze System, BIS= Behavioural Inhibition System $* \mathrm{p}<.01, * * \mathrm{p}<.001$

As Table 2 shows, using Fishers' $Z$ for testing the difference between two correlation coefficients, we find significant differences between the genders in BAS-goal-drive persistence and reward reactivity. For the female sample, low goal-drive persistent behaviour was associated with more ASB, but the opposite was found in the male sample where a negative correlation was observed. It is also noteworthy that in the male sample, we found little evidence of a correlation a between short-term reward reactivity and ASB, while for the female sample a significant positive association was observed. These results suggest that, for female participants, ASB is associated with impulsivity and poor long-term planning, whereas for male participants, ASB is related to reward-focussed strategic behaviour. 
We conducted a linear regression analysis on ASB for the male and female samples separately, with SES and each of the RST variables entered as potential predictors. The results are shown in Table 3. For the female sample, the model accounted for $28 \%$ variance in ASB, with goal-drive persistence (negative) and reward reactivity (positive) sharing independent variance with ASB. For the male sample, the model accounted for $27 \%$ variance in ASB: for these participants, reward reactivity was also a positive factor, but in contrast to the female sample, goal-drive persistence shared positive variance with ASB. 
RUNNING HEAD: RST AND ANTISOCIAL BEHAVIOUR

Table 3. Study 1, results of linear regression analysis on ASB for male and female samples and Fisher's Z comparison of effects across groups.

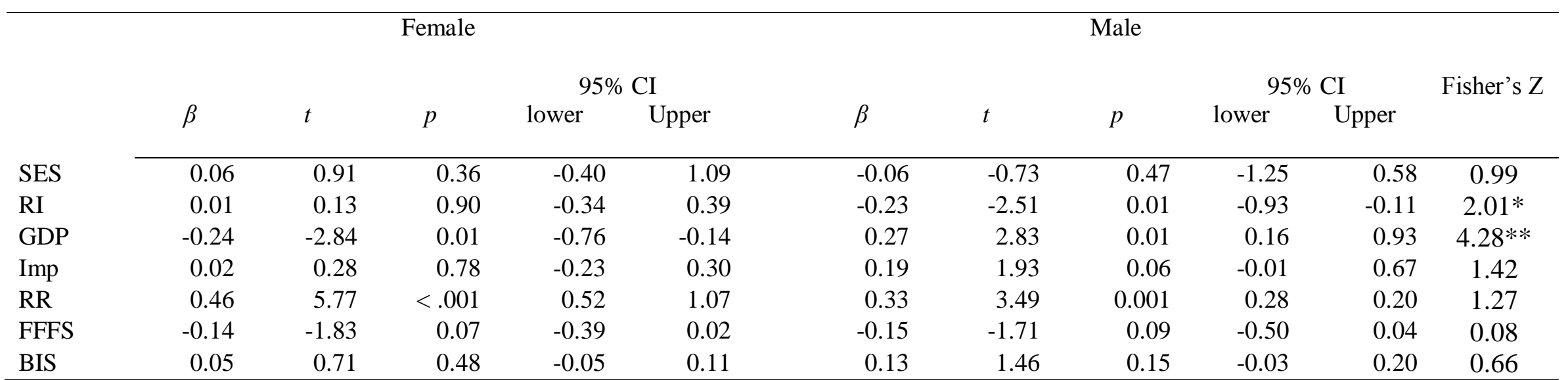

BAS= Behavioural Approach System, RI= Reward Interest, GDP= Goal-Drive Persistence, $\mathrm{RR}=$ Reward Reactivity, Imp= Impulsivity, FFFS= Fight/Flight/Freeze System, BIS= Behavioural Inhibition System.

$* \mathrm{p}<.05, * * \mathrm{p}<.001$ 
RUNNING HEAD: RST AND ANTISOCIAL BEHAVIOUR

\section{Study 1 Discussion}

Study 1 revealed a key difference in male and female samples relating to the RST BAS subfactor of goal-drive persistence. For the female sample, we found a negative association between this variable and levels of ASB, while for the male sample the association was positive: the latter result supports Morgan et al. (2014),who similarly observed heightened BAS sensitivity in male participants (they did not include females in their sample). On the basis of these findings, we suggest that this reflects a tendency among high goal-drive persistent males to use ASB (and possibly crime more generally) as a means to pursue their long-term social and personal goals in an attempt to and improve their social and personal circumstances. In Study 2, we extend this work to examine the possibility of the relevance of Strain Theory (Agnew, 2006, 2012).

\section{Study 2}

Strain theory suggests that individuals commit offences because they experience adverse life circumstances that lead to emotional and practical strains. In consequence, The goal is to escape, or cope better with, these circumstances and these goals are pursued through antisocial, rather than prosocial means. Sometimes the ASB is clearly practical, such as being short of money and stealing something to eat. In other cases, behaviours may alleviate negative emotions, possibly by using drugs or bullying. Criminal coping also occurs when people perceive that they lack the ability to deal with life situation in any other way, for instance, not having the verbal or emotional intelligence skills to deal with difficult relationships, or where violence is perceived to be an appropriate response to interpersonal conflict (Piquero et al., 2004). According to Strain Theory, the adolescent peak in ASB 
results from restricted life opportunities and choices: typically, young people have little say in terms of where they live, who with, the school they attend, etc. If these settings are distressing or abusive, there is little they can do and may turn to antisocial behaviours, such as truancy, fighting back, running away etc. in order to escape or gain a sense of control (Agnew, 1985, 2006, 2012).

Many studies which have attempted to explain adolescent ASB have suggested that social factors play a large part in its aetiology, particularly the role of parenting and disruptive family environments (Johnson et al., 2004) and factors associated with low socioeconomic status, such as poverty, low educational attainment, inequality and social exclusion. For instance, Kramer (2000) argued that structural forces reduce the ability of families and communities to provide the social support and informal social control needed to prevent ASB in young people. However, it has also been argued that ASB is not caused by low SES per se, but rather the economic problems associated with it (Agnew et al., 2008). It is also important to note evidence that ASB is a manifestation of an interaction between innate traits and social circumstances (Tuvblad, Grann, \& Lichtenstein, 2005) - for example, the effects of impulsivity are stronger in poorer neighbourhoods (Lynam et al., 2000).

In Study 2, we examine the relationship between ASB, RST traits and three types of strain known to precipitate ASB and crime (Agnew, 2006). Typically, if males who experience a lot of life strain when younger are those most likely to pursue goals though antisocial means, then we would expect to observe the same positive association between BAS goal-drive persistence and ASB as found in Study 1; however. We expect this association to be moderated: the association should be strengthened in the male sample who have experienced the most strain. 
RUNNING HEAD: RST AND ANTISOCIAL BEHAVIOUR

For our female sample, the results of Study 1 suggest that, as ASB is not goaloriented, those with least BAS goal-driven persistence should commit the most offences. Agnew $(2006,2012)$ has discussed gender differences in the influence of strains, with males typically experiencing more of those which are thought to be especially conducive to crime, such as hard discipline, poor school achievement, abusive and aggressive peers criminal victimisation and homelessness (Broidy \& Agnew, 1997; Hay, 2003); in contrast, females typically report more gender-focussed strains, such as sexual assault and intimate partner violence. While some studies have found that males typically are most likely to cope by the use of crime, other studies have suggested that girls typically living in an environment of familial and relational discord often respond antisocially, and that females typically generally tend to be more sensitive than males to strains in close relationships (Hay, 2003; Hoffman \& Su, 1997).

In Study 2, we examined three types of strain: financial, relational and familial. Based on the results of Study 1, we predicted that in the male sample would be found most influence of financial and relational strains, with males who are higher in goal-drive persistence and have experienced these strains reporting higher levels of ASB. In contrast, in the female sample, we expected to observe higher reports of ASB among participants who had experienced familial strain, though given the results of Study 1, this link may not necessarily be associated with goal-drive persistence.

\section{Method}

Participants

Study 2 extended the research to a non-student sample. Two hundred and eighty two participants were recruited from Prolific Academic, an online research platform, 166 females $\left(M_{\text {age }}=35.19, S D=11.87\right)$ and 116 males $\left(M_{\text {age }}=35.26, S D=12.74, p=.96\right)$. Recent 
RUNNING HEAD: RST AND ANTISOCIAL BEHAVIOUR

research has shown that participants recruited from the site are psychologically naïve and diverse in terms of representations of the general population (Peer, Brandimarte, Samat, \& Acquisti, 2017).

\section{Materials and Procedures}

Ethical approval was obtained from the university faculty ethics committee. Participants were supplied with a web link to the questionnaire battery, which was again hosted online by Survey Monkey. All completed the same SES, ASB and RST measures as in Study $1:$ ASB $\alpha=.91 ;$ RST, FFFS $=.79 ;$ BIS $=.94 ;$ BAS reward interest $=.81$; BAS goaldrive persistence $=.86$; BAS reward reactivity $=.85$; BAS impulsivity $=.80$.

In addition, participants completed a measure which assessed levels of strain during childhood/adolescence in three areas which have been shown to present risk for ASB (Agnew, 2006). This comprised 7 items relating to family strains (e.g., Death of a parent or other close family member; Violence, abuse of drugs and/or alcohol within family), 9 items relating to relational strains (e.g., bullying, experience of physical or emotional abuse) and 14 items relating to financial strains (e.g. Sold possessions to get cash, property repossessed). Participants were asked to indicate any of the strains which they had experienced prior to the age of 18 years (or which they recalled their family having experienced). "Yes" responses were summed to give an overall score with a higher score indicating a higher level of strain. The strain scales showed adequate reliability: family strain $\alpha=.65$, financial strain $\alpha=.73$ and relational strain $\alpha=.78$.

\section{Analysis}

Analysis was conducted as for Study 1 with one addition: the regression analysis in tested potential moderating influences of strain on ASB. In these analyses, interaction 
variables were computed as the product of the two factors in question (standardised strain $\mathrm{x}$ RST terms). The resulting variables were then used as predictors in the regression to allow us to observe whether the effects of RST factors on ASB differed as a function of strain type.

\section{Results}

No significant gender differences in reports of background SES were observed (Males $M=4.76, S D=1.60 ;$ Females $M=4.91, S D=1.42 ; p=.41, d=.09)$. Table 4 presents the descriptive statistics for the other measures. Again, in the male sample we found reports of significantly more ASB than the female sample, $t(480)=4.07, p<.001$.

Table 4.Descriptive statistics for males and females in Study 2.

\begin{tabular}{lcccc}
\hline & \multicolumn{2}{c}{ Males } & \multicolumn{2}{c}{ Females } \\
\cline { 2 - 5 } ASB & 15.14 & 9.35 & 11.01 & 7.60 \\
BAS Reward interest & 17.21 & 4.18 & 15.98 & 3.95 \\
BAS Goal drive persistence & 18.63 & 4.60 & 18.46 & 4.40 \\
BAS Reward reactivity & 25.01 & 5.78 & 26.97 & 5.12 \\
BAS Impulsiveness & 17.53 & 4.74 & 17.20 & 4.93 \\
BIS & 17.53 & 4.74 & 17.20 & 4.93 \\
FFFS & 21.11 & 6.03 & 24.42 & 5.67 \\
Family strain & 1.51 & 1.52 & 1.65 & 2.28 \\
Financial strain & 2.60 & 2.54 & 2.26 & 2.19 \\
Interpersonal strain & 2.39 & 2.02 & 1.87 & 1.95 \\
\hline
\end{tabular}

BAS= Behavioural Approach System, FFFS= Fight/Flight/Freeze System, BIS= Behavioural Inhibition System. 
MANOVA on the RST factors indicated significant effects of gender on reward interest where males score most highly, $\mathrm{F}(1,280)=6.25, \mathrm{p}=.01, \eta 2=0.2$, reward reactivity $\mathrm{F}(280)=8.90, \mathrm{p}=.003, \eta 2=.03$, and FFFS F $(280)=22.09, \mathrm{p}<.001, \eta 2=.07$ where females are the higher scorers. In terms of the three types of strain, males and females reported similar levels of each types of strain, family $\mathrm{p}=.56$, financial $\mathrm{p}=.15$ and abuse $\mathrm{p}=$ .18 .

Table 5 presents correlations for Study 2. Again, BAS impulsivity was positively correlated with ASB for both gender groups and, in line with Study1, significant gender differences were found in the relationship between ASB and both goal-drive persistence and reward reactivity: the male sample showed positive associations, while the female sample showed negative associations for goal-drive persistence and, negligible, for reward reactivity.

Table 5. Study 2, Pearson's r correlations, controlling for SES, between Antisocial Behaviour and RST traits for whole sample, and female and males samples separately, with Fisher's Z test for gender difference between correlations.

\begin{tabular}{lllll}
\hline & \multicolumn{2}{c}{ Whole Sample } & \multicolumn{1}{c}{ Female } & \multicolumn{1}{c}{ Male } \\
\cline { 2 - 4 } & & & \\
BAS-RI & .05 & $-.17^{*}$ & $.23^{*}$ & $3.32^{* *}$ \\
BAS-GDP & .07 & $-.28^{* *}$ & $.46^{* *}$ & $6.41^{* *}$ \\
BAS-RR & $.17^{* *}$ & .04 & $.41^{* *}$ & $3.23^{* *}$ \\
BAS-Imp & $.26^{* *}$ & $.28^{* *}$ & $.23^{*}$ & 0.44 \\
FFFS & .10 & .02 & -.03 & 0.41 \\
BIS & -.06 & $.21^{*}$ & .03 & 1.50 \\
\hline
\end{tabular}

BAS= Behavioural Approach System, RI= Reward Interest, GDP= Goal-Drive Persistence, RR= Reward Reactivity, Imp= Impulsivity, FFFS= Fight/Flight/Freeze System, BIS= Behavioural Inhibition System $* \mathrm{p}<.01, * * \mathrm{p}<.001$ 
RUNNING HEAD: RST AND ANTISOCIAL BEHAVIOUR

In addition, Study 2 presented gender-differences in the relationship between ASB and reward interest, with males showing a positive association and females a negative one. Female ASB was also positively associated with BIS in this study. A similar relationship was observed in Study 1, but in that case, the association did not reach statistical significance. All three of the strains showed significant positive associations with ASB in the female sample (family $r=.29$ financial $r=.41$, relational $r=.59, p<.001$, in each case); in contrast, in the male sample, this was also the case for family $(r=.37)$ and financial strains $(r=.35, p=<$ .001 , in both cases) -however, relational strain showed only a negligible relationship with ASB for males $(r=-.02)$.

We computed a linear regression that comprised the RST and strain factors as potential predictors of ASB. We conducted this analysis separately for the male and female samples and then compared the size of the influences between models using $\mathrm{z}$ tests for regressions (see Kleinbaum \& Kupper, 1978; Wuensch, 2016). As shown in Table 6, in both models, strain criteria were the strongest predictors of ASB, however, for the female sample, this was found only for relational strain while in the male sample, this was found only for financial strain. Notably, significant differences between the models were found, again, in the negative goal-drive persistence variable for the female sample and the positive goal-drive persistence for the male sample. Furthermore, the predictive value of relational strain was significantly different between the male and female samples:, a weak negative correlation for the male one and a strong positive correlation for the female one. Overall, the female sample model accounted for $46 \%$ variance in ASB, while the male sample model shared $31 \%$ variance with ASB.

We also tested potential interaction variables to investigate the predicted moderation effects of strain on the goal-drive persistence-ASB and reward reactivity-ASB relationships. 
RUNNING HEAD: RST AND ANTISOCIAL BEHAVIOUR

However, none of these showed independent predictive power or improved the fit of the models significantly ( $p>.5$ in all cases). 
Table 6. Study 2, results of linear regression analysis on ASB for the male and female samples and Fisher's Z comparison of effects across groups.

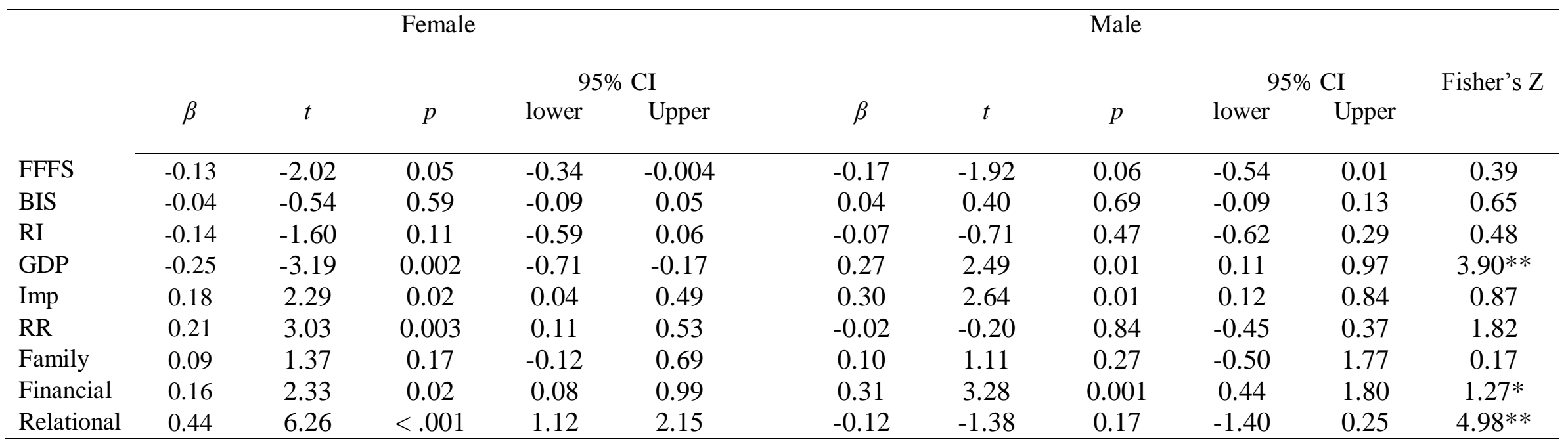

BAS = Behavioural Approach System, RI = Reward Interest, GDP = Goal-Drive Persistence, RR = Reward Reactivity, Imp = Impulsivity, FFFS = Fight/Flight/Freeze System, BIS = Behavioural Inhibition System.

$* \mathrm{p}<.05, * * \mathrm{p}<.001$ 
Overall, this second study replicated and extended the associations found in Study 1. Again, all participants showed a positive relationship between ASB and impulsivity and results further strengthened the claim that higher goal-drive persistence increases ASB in the male sample but and deters it in the female sample. In addition, Study 2 revealed that life strains has a greater impact on propensity to ASB than RST personality traits. Particularly, it was found that financial strains strongly related to ASB in the male sample while it was relational strains that appeared important in the female sample.

\section{General Discussion}

Overall, these two studies present a coherent empirical picture. They show that personality traits measured within the revised RST framework influence levels of adolescents ASB and that there are meaningful differences in the gender samples. Study 1 showed that males who reported higher levels of antisocial behaviour are impulsive, as previous research has shown, and also present with higher goal-drive persistence and reward reactivity. Females reporting antisocial behaviour are also impulsive, but in contrast to males show no evidence of goal or reward-oriented behaviour.

Study 2 examined whether goal-orientation behaviour could be related to strain, for instance whether ASB might be a way to escape or fight back against deprivation, inequality or perceived injustice. We replicated the associations of goal-drive persistence in a nonstudent population, though in this case the regression analysis suggested that BAS response reactivity was additionally influential for females as well as males. As expected, we showed that strains relating to family, financial and relational situations impact on level of ASB overall but, additionally, evidence of gender differences in the type of strain which is most predictive. Financial strains seem a significant factor for both groups, while relational factors 
RUNNING HEAD: RST AND ANTISOCIAL BEHAVIOUR

seemed additionally important for females only. In sum, individuals who experience strains in childhood and adolescence are more likely to engage in ASB, and so are individuals who are impulsive, responsive to potential rewards and, in the case of males, goal-driven and persistent in their BAS-related behaviour. However, of theoretical significance, and contrary to prediction, these strain and personality factors do not appear to interact. In other words, RST related traits and strains predict antisocial behaviour independently.

The observed differences between male and female samples in terms of their relationship between goal-drive persistence and ASB may be associated with characterisations of antisocial behaviour as either instrumental (i.e., proactive, purposeful and goal directed) or reactive (defensive, expressive and often hostile). These classifications have been widely applied to specifically aggressive behaviours (Berkwitz, 2003; Kempes, Matthys, de Vries, \& van Engeland, 2005) and to adult criminality (Piquero \& Tibbetts, 2002), and more recently have been extended to antisocial activities in adolescence such as theft, cheating and illicit drug use (Fontaine, 2006; Fontaine \& Dodge, 2006).

In the present studies, the fact that typical male ASB is consistently related to a positive association with goal-drive persistence does suggest that this behaviour is instrumental in nature, whereas typical female ASB seems more reactive, relating only to high impulsivity as well as to the BIS. Reactive ASB has been characterised as emotional, highly aroused, and responsive to a perceived provocation or threat (Fontaine, 2006) and BIS is responsive to aversive stimuli and motivates avoidance behaviours. As such, both forms of behaviour can be related to strain risk factors with males and females coping in different ways.

Much research has suggested gender differences in adolescent antisocial behaviour and its associated psychopathology in response to stressful circumstances. Young females predominate in relation to internalised disorders, such as depression and anxiety, while males 
predominate in relation to externalised, often antisocial, behaviours (Hartung, Milich, Lynam, \& Martin, 2002; Huselid \& Cooper, 1992; Leadbeater, Blatt, \& Quinlan, 1995). Group level differences between males and females are also found in the level and nature of ASB, with males typically tending to engage in more criminal and violent activities than is typically found with females, although this gender gap narrows with minor offences. Indirect aggression (such as bullying) is prevalent amongst adolescent females (Archer, 2004; Österman et al., 1998) and much of their ASB is linked to adversarial social relationships (Odgers \& Moretti, 2002). Kennedy et al. (2015) report that young female offenders present with higher incidences of childhood abuse and family conflict than non-offenders. That relational strains were predictive of ASB for females, but not males, in our Study 2 may very well reflect this finding and it may be that ASB is a reaction to these factors. In contrast, for males, financial risk factors may be a more important predictor of ASB and if their goals are to overcome these circumstances, theft or other actions to obtain final relief may clearly be instrumental in nature.

It is perhaps surprising that we did not observe the moderating effect of strain on the relationship between personality and ASB, as we predicted. One explanation may lie in the nature of our sample. Although UK student populations are increasingly heterogeneous in nature, and populations recruited through online platforms are claimed to be socially inclusive (Peer et al. 2017), it remains that individuals from the lower SES levels were underrepresented in our samples. Although participants did report ASB and the experience of strains, it may still be the case that they had protective factors (such as social support, good schooling) which, to an extent, buffered them from the negative effects. Social representativeness in participant samples has been a limitation of much research on the aetiology of ASB (Agnew et al., 2008) and emphasises how some more hard to reach sectors of society are unlikely to spontaneously engage in research. 
RUNNING HEAD: RST AND ANTISOCIAL BEHAVIOUR

In addition, we collected self-reports of ASB and delinquency and although such research methods are frequently employed, the limitations inherent in self-report must be acknowledged in that definitive conclusion about causality cannot be drawn (Lilienfeld et al, 2015). Furthermore, as we obtained retrospective reports of adolescent behaviour, some of these may have been subject to distortions related to memory or impression management. Personality traits (including those associated with RST) are thought to be relatively stable constructs, however, the need for longitudinal research to support the present findings, and to further understand how personality traits might relate to ASB and offending further into the life course.

In conclusion, the studies presented in this paper highlight how antisocial behaviour can result from life strains and dispositional motivational personality traits. Evidence for the influence of strains is well-established (Agnew 2006, 2012 for reviews) but with the present results, a more complex picture is emerging whereby not only adverse life circumstances but also inherent approach and avoidance motivational tendencies are associated with ASB.

Clearly, personality influences on ASB extend more widely than socio-emotional characteristics such as empathy and understanding, which have been the focus of much research. Traits such as goal-drive persistence and reward-reactivity are inherently motivational and offer a new way to understand more about how life stains can drive some individuals towards antisocial and criminal behaviour. Possibly the most important finding is that these effects appear to differ between male and female samples. Typically speaking, male ASB appears to be linked to 'means to an end' thinking, financial strains and personality traits associated with assiduousness and persistence. The relational strains and impulsivity traits associated with female ASB reflects a more interpersonal-reactive pattern of behaviour. Public programmes and research need to account for the diverse criminogenic 
RUNNING HEAD: RST AND ANTISOCIAL BEHAVIOUR

needs and motives of male and female offenders (Cauffman, 2008). Any truly comprehensive theory or intervention should account for such gender differences. 
RUNNING HEAD: RST AND ANTISOCIAL BEHAVIOUR

\section{References}

Agnew, R. (1985). A revised strain theory of delinquency. Social Forces, 64, 151-167. http://dx.doi.org/10.1093/sf/64.1.151

Agnew, R. (2006). Pressured into crime: An overview of general strain theory. Oxford:

Oxford University Press.

Agnew, R. (2012). Reflection on "A revised strain theory of delinquency". Social Forces, 91, 33-38. http://dx.doi.org/10.1093/sf/sos117

Agnew, R., Matthews, S. K., Bucher, J., Welcher, A. N., \& Keyes, C. (2008). Socioeconomic status, economic problems, and delinquency. Youth \& Society, 40, 159-181. http://dx.doi.org/10.1177/0044118X08318119

Archer, J. (2004). Sex differences in aggression in real-world settings: A meta-analytic review. Review of General Psychology, 8, 291-322. http://dx.doi.org/10.1037/1089$\underline{2680.8 .4 .291}$

Bacon, A. M., Burak, H., \& Rann, J. (2014). Sex differences in the relationship between sensation seeking, trait emotional intelligence and delinquent behaviour. The Journal of Forensic Psychiatry \& Psychology, 25, 673-683.

http://dx.doi.org/10.1080/14789949.2014.943796

Bacon, A.M., Lenton-Maughan, L., \& May, J. (in press). Trait emotional intelligence and social deviance in males and females. Personality and Individual Differences. 
RUNNING HEAD: RST AND ANTISOCIAL BEHAVIOUR

Brackett, M. A., Mayer, J. D., \& Warner, R. M. (2004). Emotional intelligence and its relation to everyday behaviour. Personality and Individual differences, 36(6), 1387-1402. http://dx.doi.org/10.1016/S0191-8869(03)00236-8

Broidy, L. M., \& Agnew, R. (1997). Gender and crime: A strain theory perspective. Journal of Research in Crime and Delinquency, 34, 275-306. http://dx.doi.org/10.1177/0022427897034003001

Carver, C. S., \& White, T. L. (1994). Behavioral inhibition, behavioral activation, and affective responses to impending reward and punishment: The BIS/BAS Scales. Journal of Personality and Social Psychology, 67(2), 319. http://dx.doi.org/10.1037/0022$\underline{3514.67 .2 .319}$

Cauffman, E. (2008). Understanding the female offender. The Future of Children, 18, 119142. http://dx.doi.org/10.1353/foc. 0.0015

Cohen, D., \& Strayer, J. (1996). Empathy in conduct-disordered and comparison youth Developmental Psychology, 32, 988-998. http://dx.doi.org/10.1037/0012-1649.32.6.988

Corr, P. J. (2008). Reinforcement sensitivity theory (RST): Introduction. In P. J. Corr (Ed.), The reinforcement sensitivity theory of personality (pp. 1-43). Cambridge: Cambridge University Press. 
RUNNING HEAD: RST AND ANTISOCIAL BEHAVIOUR

Corr, P. J. (2011). Anxiety: Splitting the phenomenological atom. Personality and Individual Differences (Special Issue: Anxiety), 50, 889-897.

http://dx.doi.org/10.1016/j.paid.2010.09.013

Corr, P. J. (2015). Approach, avoidance, and their conflict. In J. Wright (Ed.), International Encyclopedia of Social and Behavioral Sciences. Oxford: Elsevier.

Corr, P. J. (2016). Reinforcement sensitivity theory of personality questionnaires: Structural survey with recommendations. Personality and Individual Differences, 89, 60-64. http://dx.doi.org/10.1016/j.paid.2015.09.045.

Corr, P. J., \& Cooper, A. (2016). The reinforcement sensitivity theory of personality questionnaire (RST-PQ): Development and validation. Psychological Assessment, 28, 1427-1440. http://dx.doi.org/10.1037/pas0000273.

Corr, P. J., DeYoung, C. G., \& McNaughton, N. (2013). Motivation and personality: A neuropsychological perspective. Social and Personality Psychology Compass, 7, 158-175. http://dx.doi.org/10.1111/spc3.12016.

Corr, P. J., \& Krupić, D. (2017). Motivating personality: Approach, avoidance, and their conflict. In A. Elliott (Ed.), Advances in Motivation Science. Elsevier.

Eisenberg, N., Fabes, R. A., Guthrie, I. K., Murphy, B. C, Maszk, P., Holmgren, R., et al. (1996). The relations of regulation and emotionality to problem behavior in elementary 
RUNNING HEAD: RST AND ANTISOCIAL BEHAVIOUR

school children. Development and Psychopathology, 8(1), 141-162.

http://dx.doi.org/10.1017/S095457940000701X

Fontaine, R. G., \& Dodge, K. A. (2006). Real-time decision making and aggressive behavior in youth: A heuristic model of response evaluation and decision (RED). Aggressive Behavior, 32(6), 604-624. http://dx.doi.org/10.1002/ab.20150

Gomà-i-Freixanet, M. (1995). Prosocial and antisocial aspects of personality. Personality and Individual Differences, 19, 125-134. http://dx.doi.org/10.1016/0191-8869(95)00037-7

Gottfredson, M., \& Hirschi T. (1990). A General Theory of Crime. Stanford, Calif.: Stanford University Press.

Gray, J. A., \& McNaughton, N. (2000). The Neuropsychology of anxiety: An enquiry into the functions of the septo-hippocampal system (2nd edn.). Oxford: Oxford University Press.

Hansen, E.B., \& Breivik, G. (2001). Sensation seeking as a predictor of positive and negative risk behaviour among adolescents. Personality and Individual Differences, 30, 627-640. http://dx.doi.org/10.1016/S0191-8869(00)00061-1

Hartung, C. M., Milich, R., Lynam, D. R., \& Martin, C. A. (2002). Understanding the relations among gender, disinhibition, and disruptive behavior in adolescents. Journal of Abnormal Psychology, 111, 659-664. doi: http://dx.doi.org/10.1037/0021-843X.111.4.659

Hay, C. (2003). Family strain, gender and delinquency. Sociological Perspectives, 46, 107136. http://dx.doi.org/10.1525/sop.2003.46.1.107 
RUNNING HEAD: RST AND ANTISOCIAL BEHAVIOUR

Hoffman, J. P. \& Su, S. S. (1997). The conditional effects of stress on delinquency and drug use: A strain theory assessment of sex differences. Journal of Research in Crime and Delinquency, 34, 46-78. http://dx.doi.org/10.1177/0022427897034001004

Horvath, P., \& Zuckerman, M. (1993). Sensation seeking, risk appraisal, and risky behavior. Personality and Individual Differences, 14, 41-52. http://dx.doi.org/10.1016/0191$\underline{8869(93) 90173-Z}$

Huselid, R.F., \& Cooper, M.L. (1992). Gender roles as mediators of sex differences in adolescent alcohol use and abuse. Journal of Health and Social Behavior, 33, 348-362. http://dx.doi.org/10.2307/2137313

Johnson, J.G., Smailes, E., Cohen, P., Kasen, S., \& Brook, J.S. (2004). Antisocial parental behaviour, problematic parenting and aggressive offspring behaviour during adulthood: A 25-year longitudinal investigation. British Journal of Criminology, 44, 915-930. https://doi.org/10.1093/bjc/azh041

Jolliffe, D., \& Farrington, D. P. (2007). Examining the relationship between low empathy and self-reported offending. Legal and Criminological Psychology, 12(2), 265-286. http://dx.doi.org/10.1348/135532506X147413

Kempes, M., Matthys, W., de Vries, H., \& van Engeland, H. (2005). Reactive and proactive aggression in children: A review of theory, findings and the relevance for child and 
RUNNING HEAD: RST AND ANTISOCIAL BEHAVIOUR

adolescent psychiatry. European Child and Adolescent Psychiatry, 14, 11-19. http://dx.doi.org/10.1007/s00787-005-0432-4

Kennedy, P. J., Kelly, T. P., Grigor, J, Vale, E. L., Mason, C .L. \& Caiazza, R. (2015). Personality features of an adolescent female offending population. The Journal of Forensic Psychiatry \& Psychology, 26, 297-308. http://dx.doi.org/10.1080/14789949.2015.1007515

Kleinbaum, D. G., \& Kupper, L.L. (1978). Applied regression analysis and other multivariable methods. Pacific Grove, CA. Duxbury Press,

Kramer, R. C. (2000). Poverty, inequality, and youth violence. Annals of the American Academy of Political and Social Sciences, 567, 123-139. http://dx.doi.org/10.1177/000271620056700109

Leadbeater, B.J., Blatt, S.J., \& Quinlan, D.M. (1995). Gender-linked vulnerabilities to depressive symptoms, stress, and problem behaviors in adolescents. Journal of Research on Adolescence, 5, 1-29. http://dx.doi.org/10.1207/s15327795jra0501_1

Lilienfield, S. O., et al. 2015). Fifty psychological and psychiatric terms to avoid: A list of inaccurate, misleading, misused, ambiguous, and logically confused words and phrases. Frontiers in Psychology, 6, 1100. http://dx.doi.org/10.3389/fpsyg.2015.01100

Lynam, D. R., Caspi, A., Moffitt, T. E., Wikstr6m, P-O., H. Loeber, R. \& Novak, S. P. (2000). The interaction between impulsivity and neighborhood context on offending: The 
RUNNING HEAD: RST AND ANTISOCIAL BEHAVIOUR

effects of impulsivity are stronger in poorer neighborhoods. Journal of Abnormal Psychology, 109, 563-74. http://dx.doi.org/10.1037/0021-843X.109.4.563

Maneiro, L., Gómez-Fraguela, J.A., Cutrín, O. \& Romero, E. (2016). Impulsivity traits as correlates of antisocial behaviour in adolescents. Personality and Individual Differences, 104, 417-422. http://dx.doi.org/10.1016/j.paid.2016.08.045

Market Research Society (2016). Occupation Groupings: A Job Dictionary ( $7^{\text {th }}$ ed.). publisher??????????

Moffitt, T. E. (1993). 'Life-course persistent' and 'adolescent-limited' antisocial behaviour: A developmental taxonomy. Psychological Review, 100, 674-701. http://dx.doi.org/10.1037/0033-295X.100.4.674

Moffitt, T. E. (2006). Life-course persistent versus adolescent-limited antisocial behaviour. In D. Cicchetti \& Cohen, D. J. (Ed.). Developmental psychopathology, Vol 3: Risk, disorder, and adaptation (2nd ed.), (pp. 570-598). Hoboken, NJ: Wiley \& Sons.

Moffitt, T. E., Arseneault, L., Belsky, D., Dickson, N., Hancox, R. J., Harrington, H., Houts, R., Poulton, R., Roberts, B.W., Ross, S., Sears, M. R. Thomson, W. M. \& Caspi, A. (2011). A gradient of childhood self-control predicts health, wealth, and public safety. Proceedings of the National Academy of Sciences of the United States of America, 108, 2693-2698. http://dx.doi.org/10.1073/pnas.1010076108

Morgan, J. E., Bowen, K. L., Moore, S. C. \& van Goozen, S. H.M. (2014). The relationship between reward and punishment sensitivity and antisocial behavior in male adolescents. 
RUNNING HEAD: RST AND ANTISOCIAL BEHAVIOUR

Personality and Individual Differences, 63, 122-127.

http://dx.doi.org/10.1016/j.paid.2014.01.054

Odgers, C. L., \& Moretti, M. M. (2002). Aggressive and antisocial girls: Research update and challenges. International Journal of Forensic Mental Health, 1, 103-119.

http://dx.doi.org/10.1080/14999013.2002.10471166

Österman, K., Björkqvist, K., Lagerspetz, K.M.J., Kaukiainen, A., Landau, S.F., Fraczek, A., \& Caprara, G.V. (1998). Crosscultural evidence of female indirect aggression. Aggressive Behavior, 24,1-8. http://dx.doi.org/10.1002/(SICI)1098-2337(1998)24:1<1::AID$\underline{\mathrm{AB} 1>3.0 . \mathrm{CO} ; 2-\mathrm{R}}$

Palmer, E. J., \& Hollin, C. R. (1999). Social competence and sociomoral reasoning in young offenders. Applied Cognitive Psychology, 13(1), 79-87.

http://dx.doi.org/10.1002/(SICI)1099-0720(199902)13:1\%3C79::AIDCP613\%3E3.0.CO;2-Q

Peer, E., Brandimarte, L. Samat, S. \& Acquisti, A. (2017). Beyond the Turk: Alternative platforms for crowdsourcing behavioral research. Journal of Experimental Social Psychology, 70, 153-163. http://dx.doi.org/10.1016/j.jesp.2017.01.006

Pfefferbaum, B., \& Wood, P.B. (1994). Self-report study of impulsive and delinquent behavior in college students. Journal of Adolescent Health, 15, 295-302. http://dx.doi.org/10.1016/1054-139X(94)90602-5 
RUNNING HEAD: RST AND ANTISOCIAL BEHAVIOUR

Piquero, A. R., \& Tibbetts, S. G. (2002). Rational choice and criminal behavior: Recent research and future challenges. New York: Routledge.

Piquero, A.R., Brame, R. \& Lynam, D. (2004). Studying criminal career length through early adulthood among serious offenders. Crime \& Delinquency, 50, 412-435. http://dx.doi.org/10.1177/0011128703260333

Rutter, M. (2003). Commentary: Causal processes leading to antisocial behaviour. Developmental Psychology, 39, 372-378. http://dx.doi.org/10.1037/0012-1649.39.2.372

Tuvblad, C., Grann, M., Sarnecki, J., \& Lichtenstein, P. (2005). Pubertal timing and antisocial behavior in early and late adolescence: A longitudinal twin study. Behavior Genetics, 35, 823-823. Doi???

Wuensch, K.L. (2016). Comparing correlation coefficients, slopes, and intercepts. Retrieved from http://core.ecu.edu/psyc/wuenschk/docs30/CompareCorrCoeff.pdf on 26/07/2017.

YouGov (2016). Three quarters of Brits are 'micro-criminals'. Accessed on 02/08/2017 at https://yougov.co.uk/news/2016/10/22/three-quarters-brits-are-micro-criminals/

Zuckerman, M. (1994). Behavioral expressions and biosocial bases of sensation seeking. New York, NY: Cambridge University Press.

Zuckerman, M. (2007). Sensation seeking and risky behavior. Washington, DC: American Psychological Association. 